\title{
La reparación de las víctimas y la justiciabilidad de los derechos fundamentales en la jurisprudencia de la Corte Interamericana de Derechos Humanos
}

\section{The victim's reparation and the justiciability of fundamental rights in the case-law of the Inter- American Court of Human Rights}

\section{Lucero Ríos Tovar ${ }^{1}$ (iD}

\author{
Magíster en Derecho \\ Miembro del Grupo de Investigación de Estudios Jurídicos y Socio Jurídicos \\ Universidad Caldas, Colombia \\ Correo electrónico: lucero.rios@ucaldas.edu.co \\ https://orcid.org/0000-0001-7246-8647
}

\section{Resumen}

En este artículo se reflexiona sobre la reparación de las víctimas desde la perspectiva jurídica, en el marco de la responsabilidad internacional del Estado y con base en el Derecho Internacional de los Derechos Humanos (DIDDHH). Se presentan argumentos a favor de un traslado del estudio

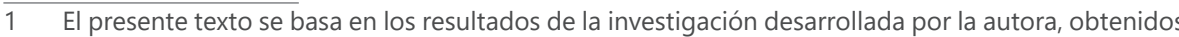
durante el proyecto doctoral bajo el título "El Derecho a la Reparación de las Víctimas como garantía de Justicia" (Ríos Tovar, 2020). 
de la reparación de las víctimas desde los componentes de la responsabilidad internacional del Estado hacia los DDHH, tomando como núcleo el concepto de víctima. Luego, se caracteriza la reparación de las víctimas como derecho humano complejo. A partir de ello, se analizan algunas Sentencias de fondo de la Corte Interamericana de DDHH (Corte IDH), para mostrar la tendencia progresiva hacia la protección de los derechos fundamentales en Latinoamérica, mediante la garantía del derecho a la reparación de las víctimas.

\section{Palabras clave}

Reparación de las víctimas, derechos fundamentales, progresividad y Corte Interamericana de DDHH (Corte IDH).

\section{Abstract}

This paper reflects on the reparation of victims from a legal perspective, withing the framework of the State's international responsibility, and based on International Human Rights Law (IHRL). Arguments are presented in favor of transferring the study of the reparation of victims from the components of the State's international responsibility towards human rights, taking as core the concept of the victim. Later, the reparation of victims is characterized as a complex human right. Therefore, some judgments on merits of the Inter-American Court of Human Rights (I/A Court H.R) are analyzed, to demonstrate the progressive inclination towards the protection of fundamental rights in Latin America, by the guarantee of the victim's right to reparation.

\section{Key Words}

Victims' reparation, fundamental rights, progressivity, Inter-American Court of Human Rights (I/A Court HR).

\section{Cómo citar este artículo:}

Ríos, L. (2020). La reparación de las víctimas y la justiciabilidad de los derechos fundamentales en la jurisprudencia de la Corte Interamericana de Derechos Humanos. Revista de la Facultad de Derecho y Ciencias Políticas, 50 (133), pp. 429-453.

doi: http://dx.doi.org/10.18566/rfdcp.v50n133.a09

Recibido: 30 de julio de 2019

Aprobado: 01 de mayo de 2020 


\section{Introducción}

Existen varias perspectivas para el análisis de la categoría de reparación de las víctimas ${ }^{2}$. De estas perspectivas sobresalen las siguientes: la perspectiva histórica y la perspectiva jurídica. La primera perspectiva, la histórica, contribuye a esclarecer las diversas formas de reparación por daños materiales e inmateriales, orientando el avance de los diferentes mecanismos de resarcimiento para las víctimas, con el objeto de saldar cuentas con el pasado y procurar la futura continuidad de los procesos de reconciliación (Elster, 2006).

Por otra parte, la segunda perspectiva, la jurídica ${ }^{3}$ ayuda a esclarecer la textura del derecho a la reparación de las víctimas, en casos de responsabilidad del Estado. Según este enfoque, la reparación es un mecanismo tanto administrativo como judicial, empleado en sociedades que —después de un conflicto armado, una amenaza terrorista o una dictadura - transitan por un "camino que permita elaborar el pasado, luego de un período de abusos y violaciones generalizadas y sistemáticas de los Derechos Humanos (DDHH), en aras de la reconciliación, el equilibrio y la estabilidad de la sociedad" (Ambos, K Malarino, E.; Elsner, G; 2009, p. 9). En estos casos, la reparación de las víctimas se relaciona con intereses como la paz, la justicia y la democracia, en el marco de lo que se ha llamado "Justicia transicional"4.

2 Esta investigación sobre la reparación como derecho humano empleó jurisprudencia de la Corte Interamericana de Derechos Humanos (Corte IDH), igualmente, se basó en un estado del arte que reunió artículos e informes de investigación, libros completos y capítulos, como contribución a textos compilatorios, a memorias de foros o encuentros científicos, tesis doctorales y de maestría. La diversidad de todo este material bibliográfico abarca un gran número de disciplinas humanas y ciencias sociales: se reunieron textos de estudios políticos, ciencias políticas, filosofía, ciencias sociales, derecho, criminología, antropología, sociología, historia, psicología y estética. Todo este conjunto de saberes compilados ofrece una imagen de cómo la reparación es un asunto que ha trascendido una percepción esquemática y eminentemente normativa (Ríos Tovar, 2020)

3 En el contexto jurídico se pueden identificar dos escenarios: 1) el sistema judicial, nacional o internacional y 2) la administración pública, a través de políticas públicas que se concretan en programas de estatales de reparación.

4 Como lo explica Teitel (2017, p. 363) "la justicia transicional de reparación no está justificada principalmente por razones correctivas convencionales, sino, en su lugar, por valores políticos externos relacionados con exigencias políticas del momento. [...] el derecho en su función de reparación, adelanta propósitos que son explícitamente políticos". Esta concepción de la reparación de las víctimas, en el campo de la Justicia Transicional, es compresible si se tiene en consideración que "la concepción de la justicia transicional [...] implica una reconceptualización de las teorías predominantes sobre el derecho y la política, así como también el énfasis de la teoría jurídica crítica sobre el papel progresivo de un Estado de Derecho plenamente vinculado a la política." (Teitel, 2017, p. 534) 
En este trabajo se adopta la perspectiva jurídica para analizar el concepto de reparación de las víctimas en el ámbito del Derecho Internacional (DI). Esto tiene por objetivo advertir la insuficiencia de los estudios realizados sobre esta categoría jurídica en el campo de la responsabilidad internacional del Estado, con el fin de exponer argumentos a favor de la fundamentación de la reparación de las víctimas a partir de las fuentes del DI de los DDHH (DIDDHH). Por consiguiente, la reparación de las víctimas será caracterizada como un derecho complejo, dado que su eficacia está ligada a los criterios de adecuación, efectividad y rapidez.

El presente texto plantea, en consecuencia, un traslado del concepto de la reparación de las víctimas, del ámbito de la responsabilidad internacional del Estado -implícita en concepciones como la Justicia transicional— al marco del DIDDHH. Para lograrlo, se analizarán los referentes teóricos y se precisarán los conceptos relacionados con la reparación de las víctimas, empleando el método deductivo. Después, se integrará los resultados obtenidos, luego de una selección y análisis, realizadas con el método inductivo, de algunas sentencias de la Corte IDH, en las cuales se ordenaron medidas de satisfacción y garantías de no repetición. Todo lo anterior permitirá demostrar la progresividad jurídica de la reparación de víctimas como un Derecho Humano, a partir de la coherencia entre las bases teóricas, los instrumentos de DIDDHH ${ }^{5}$ y los hallazgos obtenidos del análisis jurisprudencial.

\section{La reparación de las víctimas en el marco de la responsabilidad internacional del Estado}

Uno de los enfoques para el estudio de la reparación de las víctimas está orientado por la responsabilidad del Estado en el ámbito internacional. Para

5 Los Principios y directrices básicos sobre el Derecho de las Víctimas de violaciones manifiestas de las normas de DDHH y de violaciones graves del Derecho Internacional Humanitario (DIH) a interponer recursos y obtener reparaciones (2005) emitidos por la Asamblea General de la ONU en el año 2005, son un hito jurídico del Derecho Internacional de los DDHH (DIDDHH) para entender el contenido básico, el sentido y la aplicación de la categoría "reparación de víctimas". Estos principios reconocen medidas tales como: la indemnización, la rehabilitación, la satisfacción y las garantías de no repetición. Asimismo, dichos principios tienen una finalidad orientativa, respecto de las obligaciones de los Estados, al ser parte del llamado "Soft Law". Sin embargo, como se señala en este texto, la Corte Interamericana de DDHH (Corte IDH) no basa sus sentencias exclusivamente en los "Principios y Directrices", al momento de ordenar la reparación de las víctimas por medio de la implementación de medidas de diferente alcance. Lo anterior implica que el juez de la Corte IDH expande las medidas, recreando su contenido y extendiendo su aplicación. 
esta aproximación teórica es relevante analizar tres aspectos: 1) Los deberes y las obligaciones que originan la responsabilidad internacional del Estado, esto es, las fuentes de DI que las consagran; 2) Los elementos representativos del hecho internacionalmente ilícito; 3) La relación entre la obligación internacional del Estado y el comportamiento del cual, a título de acto o hecho, deriva la responsabilidad. En un estudio que adopta esta perspectiva, Pelayo y Castilla, aludiendo a la Corte Permanente de Justicia Internacional — luego Corte Internacional de Justicia—, señalan que la responsabilidad estatal "es un principio de DI, incluso una concepción general del Derecho, (el cual establece) que toda violación a un compromiso internacional implica la obligación de reparar en forma adecuada” (2012, p.9).

Si se estudia la reparación como una obligación de los Estados, los aspectos relevantes son: 1) El daño como consecuencia del incumplimiento de una obligación imputable al Estado, en este sentido, como requisito suficiente para declarar su responsabilidad; y 2) La responsabilidad internacional del Estado como presupuesto de las reparaciones. ${ }^{6}$ Asimismo, la reparación de las víctimas, concebida exclusivamente según los presupuestos de la responsabilidad internacional del Estado, es entendida como el deber de restituir a la víctima el goce de los derechos en la mayor medida posible, al emplearse mecanismos de reparación patrimonial y extra-patrimonial, que puedan ser apropiados y proporcionales a la gravedad de la violación y de las particularidades de cada caso.

Cabe advertir que este enfoque es instrumental, debido a la consideración prioritariamente patrimonial del daño como presupuesto del deber de reparar. Dicho enfoque busca una reparación a partir de la transacción económica, calculada como tasación dineraria del daño y cumplimiento de una obligación jurídica. Por ende, se reduce cualquier tipo de daño -ya sea material o inmaterial- a una cuestión económica: el dinero es empleado como un medio ágil y maleable para resolver una controversia judicial. Esto crea el riesgo de que se ignore la existencia de otros perjuicios, como consecuencia del daño. Por lo tanto, es necesario resaltar que el perjuicio revela la verdadera importancia de la reparación, al señalar los efectos del daño sobre los DDHH de la víctima, los cuales no pueden ser reducidos a una cuestión venal (Sharp, 2016).

6 En este sentido, la reparación se cataloga como un deber el Estado. Así lo denomina la Corte IDH en algunas de sus sentencias: Corte IDH, Sentencia Serie C No. 350, 2018; Corte IDH, Sentencia Serie C No. 351, 2018. 
Esta orientación instrumental prescinde de un análisis profundo de la reparación como un derecho de las víctimas: se explican y verifican solamente los requisitos para su procedencia, lo que es útil para comprender la teoría de la imputación aplicable en la responsabilidad estatal. Como manifestación de esta insuficiencia jurídica, la reparación resulta siendo una compensación o una indemnización fungible, donde el daño moral es equiparado al daño emergente 0 al lucro cesante.

En contraste con esta orientación instrumental, una reparación también debe plantear para las víctimas: 1) alternativas reales para el restablecimiento de las condiciones anteriores al daño; 2) soluciones para que puedan continuar los proyectos de vida, afectados por una serie de actos violentos contra los DDHH y 3) compromisos alrededor de la satisfacción y de la no repetición, para que violaciones juzgadas por un Tribunal no sean padecidas por otro ser humano (Van Boven, 1993; Evans, 2012).

En consecuencia, resulta evidente que el enfoque instrumental limita una justificación más sólida de la reparación, susceptible de expansión a todas las víctimas que aspiran a la justiciabilidad de sus derechos. La insuficiencia es característica de dicho enfoque, al contemplar a la reparación como 1) un deber originado por el incumplimiento de las obligaciones internacionales de los Estados y 2) el resarcimiento por la violación contra los DDHH, principalmente implementado por vías económicas-. ${ }^{7}$

\section{La reparación de las víctimas desde el enfoque de los DDHH}

El cambio de enfoque que se propone en el presente trabajo significa el traslado de la categoría de la reparación de las víctimas, desde la responsabilidad

$7 \quad$ Sobre el concepto de responsabilidad internacional del Estado, según la jurisprudencia de la Corte IDH, véanse las siguientes sentencias: Sentencia Serie C No. 352, 2018; Sentencia Serie C No. 359, 2018; Sentencia Serie C No. 363, 2018; Corte IDH, Sentencia Serie C No. 372, 2018.

8 Por consiguiente, la suficiencia, como concepto cuyo contenido es contrario a la de insuficiencia, puede definirse como el conjunto de condiciones idóneas para que se dé una reparación que trascienda el ámbito material, incorporando el DIDDHH y reconociendo la multidimensionalidad del perjuicio que han padecido las víctimas (Ríos Tovar, 2020). 
internacional del Estado, para ser estudiada dentro del ámbito del DIDDHH. ${ }^{9,10}$ La exposición anterior consideró la responsabilidad estatal a partir de un paradigma instrumental; ahora se hace necesario complementar el concepto de daño con la noción de perjuicio, a modo de condición para que la categoría de reparación de las víctimas se articule con el DIDDHH. Lo anterior implica considerar las diversas formas de violencia que pueden surgir en todo el mundo, de manera paralela con la evolución cultural, científica y política que sucede en cada generación. ${ }^{11}$ Al trascender el marco de la responsabilidad del Estado, la reparación desarrollada por medio del DIDDHH demuestra cómo el Derecho en general tiene un componente progresivo, que se propone como justificación para un garantía plena de la dignidad humana (Galdámez Zelada, 2008). En otras palabras: la reparación como Derecho Humano y como evidencia de la progresividad jurídica es resultado del Derecho en tanto disciplina que se transforma, de acuerdo con sus crisis internas y los desafíos a los que los seres humanos se enfrentan en cada época. La remisión normativa, como única búsqueda de una solución a una determinada controversia, es contraria a una visión dinámica y flexible del Derecho, como la que está implícita a lo largo de este texto.

$9 \quad$ Esto se basa en la idea expuesta en el Consejo de DDHH de las Naciones Unidas del reconocimiento progresivo del Derecho de las Víctimas de violaciones de los $\mathrm{DDHH}$ a presentar demandas de resarcimiento y Reparación, ante los mecanismos de Justicia nacionales y, subsidiariamente, ante los foros internacionales (De Greiff, 2014).

10 El Fundamento de la Reparación de las Víctimas en el DIDDHH se encuentra en: la Declaración Universal de los DDHH -DUDDHH- (Artículo 8, 1948), el Convenio Europeo para la Protección de los DDHH y de las Libertades Fundamentales-CEPDHLF (Artículo 13, 1950), el Pacto Internacional de Derechos Civiles y Políticos-PIDDCP (Artículo 2, Numeral 3, 1966), la Convención Americana sobre DDHH - CADDHH (Artículo 25, 1969), la Carta Africana sobre los DDHH y de los Pueblos CADHP, Carta de Banjul (Artículo 7, Numeral 1,1981), entre otros.

11 Los daños padecidos por las víctimas pueden también originarse por comportamientos que incurren en violaciones manifiestas a las normas internacionales de los DDHH y/o del DIH (Candia Falcón, 2015). No obstante, los conflictos padecidos por la sociedad durante el paso del tiempo, van revelando nuevas formas de violencia que surgen de asuntos tales como la desigualdad, las crisis institucionales, la geopolítica o la relación entre economía y Estado. Dichas violencias se derivan directamente de las limitaciones que la sociedad tiene para responder a las necesidades de la población más vulnerable; al mismo tiempo, ellas existen de manera sistemática, implícitas en las relaciones entre los Estados y las personas hasta mostrarse como el producto necesario de las transformaciones tecnológicas e institucionales de un periodo de tiempo determinado (Zizek, 2009; Han, 2013). Ante esto, el Derecho codificado y desarrollado en diferentes convenciones, principios y directrices puede resultar nugatorio ante nuevas victimizaciones y menoscabos a la dignidad humana. Por otra parte, una perspectiva patrimonial presente en la responsabilidad internacional del Estado no es un marco adecuado para entender y juzgar cómo las personas se convierten en víctimas de nuevas formas de ejercer la violencia. Se requiere, por lo tanto, de una interpretación integral de la sociedad a partir de una inquietud sobre la eficacia del Derecho, más allá de su uso instrumental. 
El núcleo de esta orientación es el concepto de víctima, entendida como toda persona o grupo de personas que hayan soportado daños, de manera individual o colectiva. Estos daños pueden ser desde lesiones físicas y mentales hasta el menoscabo económico o sustancial de sus DDHH. Asimismo, el concepto de víctima, de acuerdo con el Derecho de cada Estado, también puede incluir a la familia inmediata o a las personas a cargo de la víctima directa, así como a terceros que hayan podido padecer ${ }^{12}$. Dicho esto, se hace evidente que el concepto de víctima es fundamental para entender la reparación desde los DDHH (Denimal, 2016).

Esto tiene una doble razón: por una parte, porque el agente dañador, es decir el Estado, no sólo debe una indemnización; también debe garantizar que la reparación sea integral, al comprender la totalidad de los perjuicios que se derivan del daño. Por otra parte, el vínculo jurídico como condición del deber de reparar, originado por el incumplimiento del Estado de las obligaciones de respetar y garantizar ${ }^{13}$ los DDHH, puede trascender la esfera de Derechos de la víctima y extenderse a toda la sociedad.

La reparación implementada por medio de una indemnización, una rehabilitación o una restitución, puede resultar insuficiente, al partir de unos criterios eminentemente económicos para entender la realidad del daño y sus múltiples consecuencias en el proyecto de vida de las víctimas. Esto se hace más evidente en la Justicia transicional, donde los pagos y las entregas de bienes materiales son las medidas principales de reparación, dejando de lado cualquier cambio jurídico o cultural que vaya más allá de la restauración de un Estado de Derecho - el cual fue interrumpido, de manera intempestiva, por la existencia de una Dictadura, un Conflicto Armado o una Amenaza Terrorista-. Por lo anterior, es preciso que la reparación sea entendida desde una concepción dinámica y flexible del Derecho como disciplina teórica y marco para entender a la sociedad en cada época. ${ }^{14}$

12 Véase Principios y directrices básicos sobre el Derecho de las Víctimas, 2005, Numeral V.

13 Sobre estas obligaciones, los "Principios y directrices básicos sobre el Derecho de las Víctimas de violaciones manifiestas de las normas internacionales de DDHH y de violaciones graves del DIH a interponer recursos y obtener reparaciones" (2005) establecen: "I. Obligación de respetar, asegurar que se respeten y aplicar las normas internacionales de $\mathrm{DDHH}$ y el $\mathrm{DIH}^{\prime \prime}$, según lo previsto en los respectivos ordenamientos jurídicos basados en: a) Los tratados en los que un Estado sea parte; b) El Derecho Internacional (DI) consuetudinario; c) El Derecho interno de cada Estado".

14 El dinamismo y la flexibilidad de la reparación como derecho humano se predican a partir de cómo la disciplina jurídica cambia a lo largo del tiempo y busca responder a los diferentes conflictos y necesidades de las personas según un contexto socio-cultural determinado. En contraste con esta perspectiva, la Justicia transicional, cuyo fundamento es una visión instrumental del Derecho, se plantea a partir de una serie de limitaciones económicas que no permiten observar ni juzgar 
El mérito de adoptar el enfoque de los DDHH, como marco de referencia para el estudio de la reparación, consiste en que ayuda a comprender premisas como: 1) Las obligaciones del Estado se fundamentan, esencialmente, en la defensa de los DDHH. 2) El Derecho de acceso a la Justicia se materializa por medio del reconocimiento de la persona como víctima, concediendo las medidas adecuadas y efectivas para restituir sus DDHH. 3) La reparación de las víctimas es un imperativo consensuado por la comunidad internacional para remediar las graves violaciones de las normas internacionales (tanto de los DDHH como del Derecho Internacional Humanitario -DIH-), en cualquier contexto en que aquellas se hayan ocasionado (valga decir: sea o no un escenario en el que se aplique como medida de Justicia transicional).

\section{La reparación de las víctimas: un derecho complejo}

El DIDDHH evidenciado en los Principios emitidos por la ONU (2005a, 2005b) consagra los derechos de las víctimas a: 1) la reparación adecuada, efectiva y rápida por el daño sufrido; 2) el acceso igual y efectivo a la justicia y 3) el acceso a la información pertinente, sobre las violaciones y mecanismos para lograr la reparación, como recurso de las víctimas para enfrentar los efectos de las violaciones, graves y manifiestas de las normas de los DDHH y del DIH. ${ }^{15}$

Dado su carácter cualificado, la reparación es un derecho complejo porque su garantía está supeditada a varias exigencias. En este caso, la complejidad se predica del Derecho a partir de: 1) el dinamismo y la flexibilidad de su contenido y de su importancia (esto tiene que ver, como fue mencionado anteriormente,

cómo la violencia puede generar un impacto negativo, más allá de la continuidad del orden estatal (De Greiff, 2010). Estas limitaciones económicas parten de una percepción antropológica implícita, relacionada directamente con un concepto de lo humano reducido a lo económico, contrariando el dinamismo y la flexibilidad que debe tener el Derecho al momento de comprender la condición humana, sus conflictos y múltiples facetas. Por ende, una reparación estrictamente patrimonial estaría ignorando otros factores necesarios para la restauración del tejido social.

15 La Organización de las Naciones Unidas (ONU) ha ido fortaleciendo y refinando el contenido y la eficacia del DIDDHH, por medio de los siguientes instrumentos: los Principios Fundamentales de Justicia para las Víctimas de Delitos y del Abuso de Poder (1985), los Principios y directrices sobre el Derecho de las Víctimas de violaciones graves a los DDHH y al Derecho Internacional humanitario, $a$ obtener reparaciones (2005b) y el Conjunto de Principios para la protección y promoción de los DDHH mediante la lucha contra la impunidad (2005a). No obstante, debe resalltarse que su ámbito de aplicación no se encuentra restringido a contextos especiales, como las transiciones institucionales que se producen luego de dictaduras o conflictos armados (Teitel, 2003). 
con su relevancia según un periodo histórico y una serie de necesidades a resolver); y 2) Las tensiones que plantea un derecho determinado con respecto a una serie de bienes jurídicos que deben ser protegidos a largo plazo. ${ }^{16}$

Las exigencias epistemológicas y metodológicas del Derecho Complejo señalan las insuficiencias de un uso instrumental de la reparación. Estas se originan por una visión económica de la persona, que reduce todo daño moral y afectación de su proyecto de vida a un precio. Dicha visión de la reparación, presente en la responsabilidad internacional del Estado y en la Justicia transicional, es una exigencia implícita de ser aplicada al mayor número de casos posibles. En el caso de la transicionalidad, se busca una pronta reconstrucción del Estado de Derecho, tras su interrupción durante una guerra, una dictadura o un conflicto armado. ${ }^{17}$

Del cumplimiento de estas exigencias jurídicas, epistemológicas y metodológicas para fundamentar la reparación como Derecho Humano, debe seguir una serie de pasos que se exponen a continuación. En primer lugar, debe existir una adecuación entre la violación contra los DDHH, el perjuicio

16 Esta complejidad surge de cómo se desarrolla la sociedad contemporánea, en tanto no puede ser comprendida plenamente desde lógicas jurídicas de carácter deductivo y universalista. La labor del juez, por el contrario, debe partir de una perspectiva jurídica lúcida, donde los hechos determinan tanto el sentido como la eficacia de las fuentes del derecho, trascendiendo la literalidad de cualquier mandato (Kaufmann, 2007) Esto constituye el ejercicio de la adjudicación como razonamiento judicial: una lectura amplia y cuidadosa de la realidad social, por medio del Derecho y otras ciencias afines, como condición para la elaboración de una Sentencia coherente con la situación de la víctima y con la necesidad de que se implemente alguna medida de reparación (Dworkin, 1992). Igualmente, el Derecho contemporáneo debe considerar que cualquier categoría que presuma de haber descubierto de manera definitiva la esencia de la condición humana, puede resultar en interpretaciones contradictorias o en soluciones insatisfactorias con lo exigido por las víctimas: el juez debe conservar siempre un principio de realidad en el que el ejercicio del Derecho no pierda su utilidad y su semejanza con las prácticas sociales surgidas consuetudinariamente. No puede resolverse un caso por medio de un razonamiento esotérico que subestime el aporte epistemológico de otras disciplinas humanas y de las mismas víctimas (Nettel, 2006). El Derecho, como disciplina que se alimenta de otras ciencias sociales, no puede renunciar al diálogo que otros conocimientos pueden ofrecer, al momento de entender la multidimensionalidad de un daño y su consecuente victimización. Esto permite que la reparación, en tanto un Derecho Complejo, sea la suma de amplias percepciones de la naturaleza humana que desbordan cualquier presupuesto abstracto (Jullien, 2010).

17 En contraste con esto, la reparación concebida desde los DDHH hace explícitas las semejanzas entre el daño padecido por las víctimas, las consecuencias derivadas de dicho daño en un mundo complejo y el deber del Derecho de progresar, de manera flexible y dinámica, más allá de cualquier presupuesto abstracto de lo que es la humanidad (Foucault, 1996). Por consiguiente, para una aplicación más plena de la reparación como derecho humano, el Juez observa el caso no desde una serie de respuestas preestablecidas; sino desde una inquietud sobre cómo el ser humano busca mayores libertades, escapando de la posibilidad de ser reducido al estatus moral de un objeto, por medio de la violencia (Zubirí, 1982). 
sufrido por la víctima y las medidas que se adopten para su resarcimiento. Esta condición permite sugerir que la reparación es:

una categoría especial dentro de los Derechos Fundamentales, cuya titularidad está dada en la medida en que existe una especial afectación a las garantías y libertades humanas, pero también una insatisfacción de necesidades básicas o una afectación de las condiciones de igualdad para el ejercicio de las libertades garantizadas en la Constitución y la Ley (Cáceres, 2013, p. 32)

En segundo lugar, el carácter complejo del derecho a la reparación está determinado por el deber de aseguramiento efectivo, esto se traduce en la identificación de las medidas pertinentes en cada caso para restituir las condiciones existentes con anterioridad al comportamiento dañino ${ }^{18}$. De no ser esto posible, se debe compensar los perjuicios derivados de los daños producidos contra los DDHH. Para De Greiff (2010) son diferentes las categorías empleadas en el contexto del diseño de programas de reparación: en estos casos, la distinción fundamental se da entre las reparaciones materiales (compensaciones en dinero, especie o servicios) y simbólicas (disculpas oficiales, construcción de museos, etc.).

Esta distinción entre las modalidades de reparación es importante como criterio para evaluar la efectividad de las medidas de resarcimiento: sea desde el ámbito judicial con la aplicación del DI o del Derecho Interno; sea en el plano administrativo como parte de un programa público dentro de un Estado, según su propio Derecho. En consecuencia, esta distinción ofrece una imagen del grado de garantía y aseguramiento del derecho a la reparación. Además, cabe mencionar que la efectividad de este Derecho, en sus dos modalidades, judicial o administrativa, estará garantizada mientras se logre la satisfacción de los derechos de las víctimas, con fundamento en la apreciación objetiva y justa de las afectaciones derivadas del daño.

Finalmente, el carácter complejo del derecho a la reparación se sustenta en la exigencia de proveer una respuesta rápida a la reclamación de la víctima. Esta condición se vincula a otros derechos reconocidos en instrumentos internacionales como el acceso igual y efectivo a la Justicia: ya sea por medio de acciones judiciales, solicitudes de reparación administrativa — previstas en

18 Sobre la "Restitutio in Integrum", véanse: Sentencia Serie C No. 239, 2012; Corte IDH, Sentencia Serie C No. 244, 2012; Corte IDH, Sentencia Serie C No. 350, 2018); Corte IDH, Sentencia Serie C No. $351,2018$. 
los ordenamientos jurídicos internos—o, incluso, por medio de procedimientos ante instancias internacionales como la Corte IDH, cuya jurisprudencia será tema del siguiente análisis.

\section{El derecho a la reparación de las víctimas y la concepción progresiva en el DIDDHH}

En la consolidación del derecho a la reparación, la actividad de los órganos judiciales internacionales ha sido relevante, puesto que su jurisprudencia:

ha confirmado que la obligación del Estado de proporcionar Reparación se extiende mucho más allá de la compensación monetaria y abarca otras necesidades, como la investigación pública y el enjuiciamiento, la reforma jurídica, la restitución de la libertad, el empleo o las propiedades, la atención médica, y las disculpas públicas y el reconocimiento oficial de la Responsabilidad del Estado por las violaciones cometidas. (De Greiff, 2013, p. 6)

La Corte IDH ha contribuido de manera significativa a establecer el alcance de la reparación como derecho de las víctimas ${ }^{19}$. La importancia de su jurisprudencia, en relación con el derecho a la reparación, se deriva del avance logrado en la protección de los derechos fundamentales, mediante el reconocimiento de medidas de reparación ${ }^{20}$. Este efecto se puede comprender en el marco de la progresividad, el cual "implica el desarrollo constante y permanente del DIDDHH, una suerte de Derecho mínimo e irreversible, que solo admite avances y mejoras, nunca una vuelta atrás.” (Galdámez, 2008, p. 139).

19 El Sistema Interamericano está conformado por la Comisión Interamericana de DDHH (Comisión IDH) y de la Corte Interamericana de DDHH (Corte IDH). Este Sistema hace parte de la institucionalidad judicial creada por el DIDDHH junto con: a) El Sistema Europeo al que pertenece el Tribunal Europeo de DDHH, también conocido como "Tribunal de Estrasburgo" (TEDH); y b) El Sistema Africano cuyos principales organismos son la Comisión Africana sobre DDHH y de los Pueblos (Comisión ADHP) y la Corte Africana sobre DDHH y de los Pueblos (Corte ADHP).

20 Para De Greiff (2014, p. 6), "el número cada vez mayor de antecedentes jurisprudenciales del Derecho a la Reparación, en sus aspectos tanto sustantivos como de procedimiento, demuestra que el Derecho a la Reparación se ha consolidado firmemente en el DI. Los órganos creados en virtud de tratados y los tribunales nacionales, regionales e internacionales, entre ellos la Corte Internacional de Justicia, la Corte Interamericana de DDHH y el Tribunal Europeo de DDHH, han examinado un gran número de demandas individuales y de grupos dimanantes de períodos de violaciones masivas y han desarrollado una abundante jurisprudencia en la materia". 
La progresividad en el DIDDHH puede definirse por medio de las siguientes facetas: 1) La concepción progresiva: representada en la evolución de instrumentos jurídicos de protección de los DDHH, la jurisprudencia de los órganos judiciales internacionales, la constitución de sistemas regionales de protección a las víctimas y la creación de mecanismos y órganos encargados de velar por la protección y garantía de los DDHH en el mundo (Galdámez Zelada, 2008). 2) La progresividad operativa: evidenciada, según la doctrina, en “(...) el Derecho individual de queja, demanda o petición y en los procedimientos que determinan la posición del Estado demandado en casos de violaciones a los DDHH.” (Galdámez, 2008, p. 148). En el caso de las sentencias emitidas por la Corte IDH, la progresividad se hace evidente al ordenarse a los Estados que adecúen su Derecho interno al DIDDHH, siguiendo las exigencias establecidas por los artículos 1 y 2 de la CADDHH (1969). La progresividad dentro del marco del DIDDHH se da por medio del activismo judicial, al exhortarse a los Estados para que estructuren un Derecho conceptual y humanamente más eficaz, ante el impacto y el número de violaciones evidenciadas contra los DDHH (Borquez, 2017).

Si se observa el catálogo de medidas de reparación de las víctimas reconocidas por el DIDDHH -restitución, indemnización, rehabilitación, satisfacción y garantías de no repetición- desde la anterior caracterización de la progresividad, se resalta que son las dos últimas modalidades las que tienen un mayor potencial para refinar y fortalecer el sentido y la eficacia de la reparación, respecto de la victimización en un contexto concreto. Ambas medidas pueden dar cabida a exigencias que no se agotan en lo monetario, considerando la necesidad de cohesionar una sociedad vulnerada por la violencia, ya que es un atentado grave contra los DDHH de una o varias personas. La satisfacción y garantías de no repetición ofrecen un conjunto de mandatos básicos para que las víctimas puedan recuperar su dignidad y continuar con sus proyectos de vida.

En seguida, se mostrarán los hallazgos obtenidos del análisis realizado con algunas sentencias de la Corte IDH, con el fin de evidenciar el desarrollo progresivo del derecho a la reparación de las víctimas como DDHH. 


\section{Análisis de sentencias de la Corte IDH: progresividad y reparación a las víctimas como derecho humano}

Las Sentencias de la Corte IDH son fuentes jurídicas que aportan una justificación ${ }^{21}$ para proteger los DDHH. Por medio de su jurisprudencia, la Corte IDH demuestra una percepción sutil, al interpretar las condiciones espaciotemporales que llevaron a la victimización; así como una creatividad jurídica, al momento de ordenar a los Estados una serie de acciones, considerando la vulnerabilidad de las víctimas. ${ }^{22}$

Para la Corte IDH, las reparaciones tienen como propósito la desaparición de las consecuencias de las violaciones contra los DDHH. Dadas estas, se determina tanto su naturaleza como su tasación en aspectos materiales e inmateriales. Al mismo tiempo, se exige que las reparaciones no enriquezcan ni empobrezcan a las víctimas ni a sus familiares (Corte IDH. Sentencia Serie C No. 282, 2014). ${ }^{23}$ En una sentencia más reciente, la Corte reiteró esta misma jurisprudencia, señalando cómo la reparación es un deber que surge ante las múltiples consecuencias de un perjuicio padecido por las víctimas, que menoscaba sus DDHH. ${ }^{24}$

El fundamento normativo de la relación entre reparación, derechos y daño es el artículo 63.1 de la CADDHH (1969). Dicho artículo le otorga competencia

21 Las Sentencias de la Corte IDH son vinculantes para los Estados que han ratificado la CADDHH, en el marco de la convencionalidad, entendida como la categoría jurídica que exige la adecuación del Derecho Interno de los Estados a la interpretación jurisprudencial que realiza laCorte IDH de la CADDHH y demás normas del DIDDHH (Santofimio Gamboa, 2017).

22 Aunque la jurisprudencia de la Corte IDH sigue presentando algunas deficiencas que pueden restarle continuidad a su perspectiva deóntica, basada en una interpretación profunda del DIDDHH. Por ejemplo: el que no exista una jurisprudencia unificada sobre el contenido de los conceptos "violencia", "víctimas", "daño" o "reparación". Esto propicia que en cada caso asuma un significado distinto de esos términos, sin tener en cuenta los antecedentes jurídicos. (Ríos Tovar, 2020).

23 Un precedente de la Corte IDH es la Sentencia Serie C No. 76, párr. 79, 2001.

24 Según la Sentencia Serie C No. 351 (2018): “(...) se presentan (sic) una diversidad de afectaciones tanto en la esfera individual como colectiva. (Las víctimas) sufren distintas afectaciones por la búsqueda de justicia no sólo de carácter material, sino también (sic) otros sufrimientos y daños de carácter psicológico, físico y en su proyecto de vida, así como otras posibles alteraciones en sus relaciones sociales y la dinámica de sus familias y comunidades. Frente a ello, la Corte ha considerado la necesidad de otorgar diversas medidas de reparación, a fin de resarcir los daños de manera integral, por lo que además de las compensaciones pecuniarias, las medidas de satisfacción, restitución, rehabilitación y garantías de no repetición tienen especial relevancia por la gravedad de las afectaciones y el carácter colectivo de los daños ocasionados." Asimismo, el desarrollo del concepto de reparación, en relación con los diversos perjuicios en las esferas privada y colectiva, está presente en las siguientes sentencias: Corte IDH, Sentencia Serie C No. 211, 2009; Corte IDH, Sentencia Serie C No. 244, 2012; Corte IDH, Sentencia Serie C No. 350, 2018. 
a la Corte IDH para: 1) declarar la ocurrencia de una violación a un derecho o libertad, protegidos por la CADDHH ${ }^{25}$; 2) Disponer que se garantice el goce del derecho vulnerado al afectado y 3) Ordenar que se reparen los efectos del daño. ${ }^{26}$ En consecuencia, la Corte IDH ha consolidado su jurisprudencia sobre las reparaciones, al considerar que la violación de una obligación internacional que haya producido un daño implica el deber de repararlo adecuadamente. Asimismo, la Corte IDH ha establecido que esta interpretación del artículo 63.1 de la CADDHH (1969) recoge una norma consuetudinaria, el cual es uno de los principios fundamentales del DI contemporáneo sobre la responsabilidad del Estado (Corte IDH, Sentencia Serie C No. 342, 2017)

Por otra parte, una de las modalidades de la concepción progresiva ${ }^{27}$ se concreta en las Sentencias de la Corte IDH. Estas complementan conceptos y nociones mencionados en instrumentos de $\mathrm{DI}^{28}$ como la "justa indemnización ${ }^{29}$ ", la compensación ${ }^{30}$ y la "Restitutio in Íntegrum"31. Esto se hace con el fin de proveer, según las circunstancias de cada caso y de acuerdo con los perjuicios padecidos por la víctima, una reparación integral que pueda impactar su vida cotidiana y el marco jurídico nacional. En efecto, en la jurisprudencia de la Corte IDH se han venido ordenando medidas de satisfacción ${ }^{32}$ y garantías de no repetición ${ }^{33}$ a favor de las víctimas. Estas medidas se pueden considerar

25 Sobre esta relación entre daño y derechos, Nash (2009, p. 38) explica que: "a juicio de la Corte, la Responsabilidad no puede extenderse a elementos ajenos de aquellos efectos inmediatos del acto. Además, dichos efectos inmediatos deben estar jurídicamente tutelados, lo cual nos lleva a la idea de que el efecto dice relación con el bien jurídico protegido a partir del Derecho o libertad consagrada en la Convención".

26 Las indemnizaciones compensatorias fueron tratadas por la Corte IDH en la Sentencia Serie C No. 359, 2018.

27 Sobre un entendimiento básico de la progresividad según la jurisprudencia interamericana, véase: Corte IDH, Sentencia Serie C No. 211, 2009.

28 Debe resaltarse que, en la jurisprudencia de la Corte IDH se mencionan tres términos que aluden a los componentes de la reparación: justa indemnización, compensación, e indemnizaciones compensatorias. Asimismo, estos términos son relacionados con la reparación integral como concepto teleológico de la reparación. Véanse las siguientes sentencias: Corte IDH, Sentencia Serie C No. 350, 2018; Corte IDH, Sentencia Serie C No. 363, 2018).

29 Sobre la noción de justa indemnización, véase las siguientes sentencias: Corte IDH, Sentencia Serie C No. 177, 2008; Corte IDH, Sentencia. Serie C No. 219, 2010).

30 Sobre la compensación como medida de reparación, la Corte IDH se pronunciado en las siguientes sentencias: Corte IDH, Sentencia Serie C No. 352, 2018; Corte IDH, Sentencia Serie C No. 356, 2018).

31 Sobre la restitución integral, véase esta sentencia: Corte IDH, Sentencia Serie C No. 350, 2018).

32 Sobre la satisfacción como medida de reparación y su potencial para la progresividad, la Corte IDH se ha expresado en las siguientes sentencias: Corte IDH. Sentencia Serie C No. 177, 2008.; Corte IDH, Sentencia Serie C No. 359, 2018.; Corte IDH, Sentencia Serie C No. 363, 2018.

33 Sobre las garantías de no repetición en relación con la progresividad, la Corte IDH se ha pronunciado en las siguientes sentencias: Corte IDH, Sentencia Serie C No. 197, 2009; Corte IDH, Sentencia Serie C No. 351, 2018; Corte IDH, Sentencia Serie C No. 359, 2018; Corte IDH, Sentencia Serie C No. 363, 2018. 
como estándares de protección a los derechos fundamentales, con efecto progresivo para el DIDDHH. ${ }^{34}$ Lo afirmado aquí se ilustra a continuación, con el análisis de algunas sentencias de la Corte IDH: en ellas se ordenaron medidas de reparación con el fin de amparar derechos fundamentales, más allá de las pretensiones invocadas por las víctimas y sus representantes.

\subsection{Derecho a la integridad personal: caso Favela Nova Brasilia Vs. Brasil (2017) 35}

La Corte IDH decidió sobre la responsabilidad internacional del Estado de Brasil por la ejecución extrajudicial de 26 personas, la tortura y violencia sexual contra 3 mujeres, actos que habrían sido cometidos durante dos redadas llevadas a cabo por agentes de la Policía Civil de Río de Janeiro el 18 octubre de 1994 y el 8 mayo de 1995 en la Favela Nova Brasilia. En su sentencia, la Corte IDH consideró que la falta de investigación de los hechos y la prolongada impunidad causaron la violación contra los derechos a las garantías judiciales, la protección judicial y la integridad personal. Dichas violaciones están contempladas, respectivamente, en los artículos 8.1, 25 y 5.1 de la CADDHH (1969), relacionados con los artículos 1.1. y 2 de la misma norma (1969). Asimismo, la Corte IDH declaró la infracción de los artículos 1, 6 y 8 de la Convención Interamericana para Prevenir y Sancionar la Tortura (1985) y el artículo 7 de la Convención “Belém do Pará” (1994).

El razonamiento de la Corte IDH sobre los daños causados por la violación contra los derechos humanos hizo evidente la existencia de un perjuicio, un deterioro psíquico y moral, manifestado en una angustia y un profundo sufrimiento que afectaron la integridad personal de las víctimas. En estas circunstancias, la Corte IDH determinó que las víctimas padecieron una alteración negativa en el desarrollo normal de sus actividades diarias y en su proyecto de vida en general, consistente en cambios continuos de domicilio y trabajo, en el retiro del sistema educativo y en la necesidad de emprender una

34 Según Ferrajoli (2001,P. 19), los Derechos Fundamentales son aquellos Derechos subjetivos que corresponden universalmente a "todos los seres humanos en cuanto dotados del status de persona, de ciudadanos o personas con capacidad de obrar; entendiendo por "Derechos subjetivos" cualquier expectativa positiva (de prestaciones) o negativa (de no sufrir lesiones) adscrita a un sujeto por una norma jurídica; y por "status", la condición de un sujeto, prevista asimismo por una norma jurídica positiva, como presupuesto de su idoneidad para ser titular de situaciones jurídicas y/o autor de los actos que son ejercicio de éstas."

35 Corte IDH, Sentencia Serie C No. 333, 2017. 
vida laboral a edad temprana. Esta afectación fue consecuencia de la extrema desprotección y vulnerabilidad en la que se encontraron.

Tras la valoración del perjuicio, la Corte IDH dispuso que el Estado de Brasil realizara acciones reparatorias, consistentes en medidas de satisfacción y garantías de no repetición para las víctimas como la publicación de la sentencia, la realización de un acto público de reconocimiento de responsabilidad y la develación de placas conmemorativas. Además, la Corte IDH ordenó que Brasil llevara a cabo acciones para garantizar los DDHH de otras personas quienes, aunque no fueron declaradas como víctimas directas, pueden llegar a sufrir violaciones contra sus DDHH de manera semejante. Por consiguiente, la Corte IDH exigió la adopción de las siguientes medidas de reparación: 1) La implementación del control externo del Ministerio Público en casos de violencia policial, más allá de la supervisión a distancia de las investigaciones realizadas por delegados de la propia policía. 2) El establecimiento de políticas para la disminución de la letalidad y de la violencia policial. 3) La creación de un programa o curso permanente y obligatorio sobre atención a mujeres víctimas de violación sexual, dirigido a todos los niveles jerárquicos de las Policías Civil y Militar de Río de Janeiro y a funcionarios de atención de salud.

El sentido de la progresividad del derecho a la reparación de las víctimas, demostrado por esta jurisprudencia, se halla en el razonamiento del Juez internacional de DDHH, quien está dispuesto a ponderar el perjuicio de las víctimas y, con ello, advertir sobre la necesidad de extender el alcance de las reparaciones y dotarlas de contenido, para lograr una garantía efectiva de los DDHH de todas las personas.

\subsection{Derecho a la salud: caso Cuscul Pivaral y otros Vs. Guatemala $(2018)^{36}$}

En el momento en que la Corte IDH emitió la sentencia declarando la responsabilidad internacional del Estado de Guatemala, los hechos de este caso estaban relacionados con la situación de 34 personas que vivían con el Virus de Inmunodeficiencia Humana (VIH), de otras 15 personas que ya habían fallecido a causa de esta condición y de sus familiares, quienes padecieron la falta de una apropiada atención médica estatal y de una adecuada protección judicial.

36 Corte IDH, Sentencia Serie C No. 359, 2018. 
En razón de ello, se constató la violación contra el derecho a la salud (según el artículo 26 de la CADDHH, 1969) por la falta de atención médica y la discriminación relacionada con el padecimiento de una patología. Igualmente, se evidenció la violación contra el principio de progresividad, los derechos a la vida y a la integridad personal (artículo 4, en relación con el artículo 26 de la CADDHH, 1969), el derecho a la integridad personal (artículo 5 en referencia al artículo 26 de la CADDHH, 1969), los derechos a las garantías procesales y a la protección judicial (artículos 8.1 y 25.1 de la CADDHH, 1969) y el derecho de la integridad personal de los familiares de las víctimas (artículo 5.1 de la CADDHH, 1969). Todos estos derechos mencionados están vinculados al artículo 1.1 de la misma CADDHH (1969).

El perjuicio que padecieron los pacientes con VIH consistió en el sufrimiento que les causaron las secuelas físicas y psíquicas, ocasionadas por las enfermedades oportunistas, además de los factores sociales derivados de su condición. Para sus familiares, el perjuicio se representó en los sentimientos de dolor, angustia e incertidumbre por la falta de atención médica oportuna y la carencia de medicamentos; así como en la frustración e impotencia que sintieron por carecer de los medios económicos para proporcionar el tratamiento necesario a sus seres queridos. Además, la situación los obligó a cambiar drásticamente su forma de vida (modificar dinámicas laborales, interrumpir o cancelar sus proyectos educativos, cambiar de país de residencia, etc.), lo que trajo como consecuencia la ruptura familiar, el menoscabo de la economía familiar y, en general, la destrucción de su proyecto de vida. Finalmente, la Corte IDH constató que el sufrimiento padecido por los familiares de las víctimas también ocurrió debido a la estigmatización de las personas que viven con VIH. Esto hizo que experimentaran sentimientos de vergüenza y miedo, perdieran sus empleos e incluso fueran excluidos de sus núcleos familiares.

En consonancia con la magnitud de los perjuicios padecidos por las víctimas y sus familiares, la Corte IDH ordenó la reparación de sus DDHH. Como medidas de satisfacción y garantías de no repetición, la Corte IDH dispuso que el Estado de Guatemala: 1) Realizara un acto público de reconocimiento de responsabilidad internacional. 2) Publicara y difundiera la sentencia. 3) Otorgara becas para que las hijas e hijos de las víctimas directas accedieran a la educación universitaria de carácter público.

Adicionalmente, la Corte IDH contribuyó en este caso a la progresividad del derecho a la Reparación de las Víctimas, dotando de sentido a las medidas de satisfacción y a las garantías de no repetición para hacer coherente su 
expansión hacia todas las personas que puedan llegar a experimentar perjuicios semejantes, como los sufridos por las víctimas y sus familiares. En este orden de ideas, la Corte IDH dispuso que el Estado de Guatemala debe: 1) Implementar mecanismos efectivos de fiscalización y supervisión periódica de los hospitales públicos para asegurar una atención integral en materia de salud a personas que viven con VIH. 2) Instaurar un sistema de información sobre el alcance de la epidemia de VIH en el país. 3) Instituir un sistema que le permita hacer un diagnóstico de la atención prestada a la población que vive con VIH. 4) Diseñar un mecanismo para garantizar la accesibilidad, disponibilidad y calidad de los antirretrovirales, los exámenes diagnósticos y las prestaciones en salud para la población con el VIH. 5) Establecer un programa de capacitación acerca de los estándares internacionales y la legislación nacional en materia de tratamiento integral para personas que viven con VIH para los funcionarios del sistema de salud que trabajen en hospitales y unidades de atención médica y que atienden, especialmente, a personas con VIH en Guatemala. 6) Garantizar que las mujeres embarazadas tengan acceso a una prueba de VIH, dándoles seguimiento periódico y un tratamiento médico adecuado, para evitar la transmisión vertical del virus. 7) Diseñar recursos y publicaciones para informar sobre la prevención de la transmisión de VIH, sobre el peligro de la transmisión vertical de este y sobre la reducción del riesgo. 8) Realizar una campaña nacional de concientización y sensibilización -dirigida a toda la población en general y, en especial, a los funcionarios públicos y a los sectores sanitariamente vulnerables- sobre los derechos de las personas que viven con VIH, sobre las obligaciones que las autoridades tienen respecto de su atención y sobre la necesidad de respetar a las personas que viven con esta condición. Todo esto debe ser presentado en un lenguaje que incorpore la perspectiva de género y que sea comprensible para toda la población.

\subsection{Derecho a la libertad de asociación: caso Escaleras Mejía y otros Vs. Honduras $(2018)^{37}$}

La Corte IDH declaró que el Estado de Honduras fue responsable por la privación de la vida del señor Carlos Escaleras Mejía quien recibió dos disparos por la espalda el día 18 de octubre de 1997. El sustento fáctico de esta decisión fue la comprobación de que la causa del daño fue el rechazo de la víctima a aceptar las ofertas de dinero que recibió, a cambio de retirar su candidatura en una campaña electoral. Asimismo, se comprobó que la víctima fue presionada a abandonar el movimiento de lucha por el medio ambiente y

37 Corte IDH, Sentencia Serie C No. 361, 2018. 
que recibió amenazas por encabezar las protestas relacionadas con la decisión de construir instalaciones militares donde existía una cuenca de agua, porque dichas instalaciones impedirían el acceso del recurso hídrico de los habitantes de distintas poblaciones.

En cuanto al fundamento jurídico de la declaratoria de responsabilidad internacional del Estado, la Corte IDH constató la violación de los derechos a la vida, a la libertad de asociación y a derechos políticos, (artículos 4.1, 16.1 y 23.1 de la CADDHH, 1969) en relación con el artículo 1.1 (1969) del mismo instrumento internacional, en perjuicio de Carlos Escaleras Mejía. Igualmente, la Corte IDH determinó que los familiares sufrieron la violación contra sus derechos a la integridad personal, a las garantías judiciales y a la protección judicial (artículos 5.1, 8.1 y 25.1 de la CADDHH 1969). Todos estos derechos violados tienen relación con el artículo 1.1 (1969) de este mismo instrumento internacional.

Para la Corte IDH, el daño representado en la violación contra los DDHH de la víctima y sus familiares desencadenó para estos últimos un perjuicio, debido a la angustia que experimentaron durante la búsqueda de justicia, por la falta de protección efectiva y por el sufrimiento profundo, derivado del cambio total de sus vidas. Por ello, la Corte IDH aceptó homologar el acuerdo celebrado entre las partes con respecto a la medida de satisfacción, consistente en el otorgamiento de garantías para la educación secundaria y universitaria de los jóvenes hijos del señor Carlos Escaleras.

Adicionalmente, esta sentencia expuso una argumentación a favor de la importancia de la labor que cumplen las defensoras y defensores de DDHH, debido a su contribución significativa para el fortalecimiento de la democracia y del Estado de Derecho. Se les reconoció su contribución esencial en la observancia de los DDHH, como miembros de la sociedad que colaboran para el logro de los fines de los Estados y del sistema interamericano como un todo. Por esta razón, la Corte IDH declaró homologadas las medidas de satisfacción y las garantías de no repetición, que tienen una aplicación para personas que no fueron declaradas víctimas; pero que merecen una protección especial, porque su labor ayuda a garantizar los DDHH en toda la sociedad.

De esta manera, la reparación de las víctimas en el caso estudiado alcanza un desarrollo progresivo, al materializarse en medidas de satisfacción y garantías de no repetición consistentes en: 1) la realización y transmisión de un documental televisivo, con una duración de diez minutos, el cual registre la labor del señor Carlos Escaleras Mejía como activista y defensor de los 
recursos naturales. 2) La implementación de un proceso de capacitación en temáticas ambientales a docentes del área de secundaria, para que puedan aplicar las Guías Metodológicas de Gestión de Riesgo y Educación Ambiental. 3) La aprobación e implementación de un protocolo de debida diligencia en la investigación de delitos cometidos en contra de personas defensoras de DDHH. En esta sentencia, el Juez Interamericano contribuye a la evolución progresiva del derecho a la reparación de las Víctimas, porque aporta razones que justifican la necesidad de ordenar, como medidas de satisfacción y garantías de no repetición, la ejecución de planes, procesos y programas para la protección de las defensoras y defensores de DDHH. Ellas y ellos son considerados como miembros de una colectividad, cuya labor tiene notable importancia para toda la sociedad.

\section{Conclusiones}

En el DI, el término “reparación de las víctimas” ha sido estudiado en el marco de la responsabilidad internacional del Estado. Con esta orientación, se considera la reparación de las víctimas como: 1) la consecuencia jurídica del incumplimiento de las obligaciones, establecidas en tratados y convenios internacionales; 2) la respuesta al daño causado por la violación contra los DDHH y 3) un deber a cargo del Estado. En contraste, a lo largo de este artículo, se ha propuesto un giro en la orientación del estudio de la reparación de las víctimas, para ubicarla en el ámbito de los DIDDHH.

Con esta perspectiva, se sustentó la naturaleza de la reparación de las víctimas como un derecho humano, cualificado según las normas internacionales como adecuado, efectivo y rápido. Esto proporciona una serie de criterios específicos para valorar su cumplimiento y eficacia. Bajo esta consideración, la reparación ha sido denominada aquí como un "Derecho Humano Complejo”, en tanto que su garantía está condicionada por una serie de exigencias que deben cumplir los Estados: ellos adquieren la obligación de reparar a las víctimas, por medio de programas administrativos o como efecto de una sentencia emitida por un órgano judicial (sea nacional o internacional).

Finalmente, con el análisis de algunas sentencias, el cual combinó los métodos inductivo y deductivo, se mostró cómo la Corte IDH ha contribuido a la progresividad del DIDDHH, exigiendo la protección de los DDHH y el restablecimiento de su goce efectivo -a través de medidas de satisfacción y de garantías de no repetición, cuyo contenido y aplicación se hace extensible a todo el conjunto de la sociedad-. 


\section{Referencias bibliográficas}

\subsection{Textos Citados}

Ambos, K.; Malarino, E.; Elsner, G. (Ed). (2009). Justicia de Transición: informes de América Latina, Alemania, Italia y España. Konrad Adenauer Siftung; GeorgAugust- Universität Götingen: Instituto de Ciencias Criminales - Departamento de Derecho Penal Extranjero e Internacional.

Borquez, N. (2017). Hacia una igualdad transformadora en las producciones de la corte y de la comisión interamericana de derechos humanos: derechos sociales, mujeres y maquilas. Revista Electrónica Instituto de Investigaciones Jurídicas y Sociales A. L. Gioja: http://www.derecho.uba.ar/revistas-digitales/index.php/revista-electronicagioja/article/view/335/259.

Cáceres Mendoza, A. E. (2013). ¿Reparar?, bueno, si. Pero, ¿Por qué?. Una mirada hacia la fundamentación de la obligación de reparar integralmente a las Víctimas en Colombia. [Tesis de maestría, Universidad Nacional de Colombia] Repositorio Institucional UN. http://bdigital.unal.edu.co/9861/1/06700971.2013.pdf

Candia Falcón, G. (2015). Derechos Implícitos y Corte Interamericana de Derechos Humanos: una reflexión a la luz de la noción de Estado de Derecho. Revista Chilena de Derecho, 42( 3), 873 - 902.

De Greiff, P. (Ed). (2010). The Handbook of Reparations. Oxford University Press.

De Greiff, P. (2013). Promoción de la verdad, la justicia, la reparación y las garantías de no repetición. Informe del relator especial ante la Asamblea General de las Naciones Unidas. https://www.ohchr.org/Documents/HRBodies/HRCouncil/RegularSession/ Session21/A-HRC-21-46_sp.pdf

De Greiff, P. (2014). Promoción de la verdad, la justicia, la reparación y las garantías de no repetición. Informe del relator especial ante la Asamblea General de las Naciones Unidas. https://documents-dds-ny.un.org/doc/UNDOC/GEN/N14/564/70/PDF/ N1456470.pdf?OpenElement

Denimal, M. (2016). La réparation intégrale du préjudice corporel: réalités et perspectives. Université de Lille 2: Droit et Santé: https://tel.archives-ouvertes.fr/ tel-01447888/document

Dworkin, R. (1992). El Imperio de la Justicia. Gedisa.

Elster, J. (2006). Rendición de cuentas: la justicia transicional en perspectiva histórica. Katz Editores.

Evans, C. (2012). The Right to Reparation in international Law for Victims of Armed Conflict. Cambridge University Press, Cambridge Studies in International and Comparative Law.

Ferrajoli, L. (2001). Los fundamentos de los derechos humanos. Editorial Trotta.

Foucault, M. (1996). La Verdad y las Formas Jurídicas. Gedisa.

Galdámez Zelada, L. (2008). La progresividad en la jurisprudencia de la Corte Interamericana de Derechos Humanos. Revista de Derecho de la Universidad Católica del Norte, Chile: https://revistas.ucn.cl/index.php/revista-derecho/article/ view/1872

Han, B. C. (2013). Topología de la Violencia. Editorial Herder.

Jullien, F. (2010). De lo Universal, de lo Uniforme, de lo Común y del Diálogo entre las Culturas. Editorial Siruela. 
Kaufmann, A. (2007). La Filosofía del Derecho en la Posmodernidad. Temis.

Nash Rojas, C. (2009). Las Reparaciones ante la Corte Interamericana de Derechos Humanos (1988 - 2007). Universidad de Chile, Facultad de Derecho, Centro de Derechos Humanos.

Nettel, A. M. (2006). La Distinción entre contexto de descubrimiento y de justificación y la racionalidad de la decisión judicial. Revista Isonomía, No. 5, 107 - 117.

Pelayo Möller, C. M. y Castilla Juárez, K. A. (2012). La Teoría de las Reparaciones a la luz de los Criterios de los Tribunales Internacionales de Derechos Humanos. Comisión de Derechos Humanos del Distrito Federal, Servicio Profesional en Derechos Humanos: http://cdhdf.org.mx/serv_prof/pdf/formacionprofderechointllateoriadelas.pdf.

Ríos Tovar, L. (2020). El Derecho a la Reparación de Víctimas como Garantía de Justicia. [documento inédito][Tesis de Doctorado en Derecho Universidad de Medellín].

Saavedra. (2013). Teoría de las Reparaciones a la Luz de los Derechos Humanos. Suprema Corte de Justicia de la Nación (scjn), Oficina en México del Alto Comisionado de las Naciones Unidas para los Derechos Humanos(oacnudh) y Comisión de Derechos Humanos del Distrito Federal de México (cdhdf): http://cdhdfbeta.cdhdf.org.mx/ wp-content/uploads/2015/05/7-Teor\%C3\%ADa-reparaciones.pdf.

Santofimio Gamboa, J. O. (2017). El control de convencionalidad: vicisitudes para su construcción sustancial en el Sistema Interamericano de Derechos Humanos: ideas fuerza rectoras. Universidad Externado de Colombia.

Sharp, D. N. (2016). Transitional justice and liberal post-conflict governance : synergies and symmetries, frictions and contradictions. [Doctoral Thesis] University of Leiden Repository: https://openaccess.leidenuniv.nl/handle/1887/37292

Teitel, R. (2003). Transitional Justice Genealogy Harvard Human Rights Journal, Vol. 16, Cambridge, MA, pp. 69-94.

Teitel, R. (2017). Justicia Transicional. Universidad Externado de Colombia.

Van Boven, T. (1993). Estudio relativo al derecho a la restitución, indemnización y rehabilitación a las víctimas de violaciones flagrantes de los derechos humanos y las libertades fundamentales. Naciones Unidas, Comisión de Derechos Humanos, Subcomisión de Prevención de Discriminaciones y Protección a las Minorías, Equipo Nlzkor: http://www.derechos.org/nizkor/espana/doc/boven.html

Zizek, S. (2009). Sobre la Violencia: Seis Reflexiones Marginales. Paidós.

Zubirí, X. (1982). El hombre, realidad personal. En X. Zubirí, Siete Ensayos sobre Antropología Filosófica (pp. 79-87). Universidad Santo Tomás, Centro de Enseñanza Desescolarizada.

\subsection{Documentos Jurídicos}

Carta Africana Sobre los DDHH y de los Pueblos (Carta de Banjul) [CADHP]. (1981). XVIII Asamblea de Jefes de Estado y Gobierno de la Organización de la Unidad Africana. http://www.acnur.org/t3/fileadmin/scripts/doc.php?file=t3/fileadmin/ Documentos/BDL/200 2/1297

Convención Interamericana para Prevenir y Sancionar la Tortura. (1985). Washington, EE.UU. Organización de Estados Americanos (OEA). https://www.oas.org/juridico/ spanish/tratados/a-51.html

Convención Interamericana para Prevenir, Sancionar y Erradicar la Violencia contra la Mujer. (1994). Belém do Pará, Brasil. Organización de Estados Americanos (OEA). https://www.oas.org/es/mesecvi/docs/BelemDoPara-ESPANOL.pdf 
Conjunto de principios para la protección y la promoción de los DDHH mediante la lucha contra la impunidad -Principios de Orentlicher-. (2005a). Naciones Unidas, Comisión de DDHH. http://www.Derechos.org/nizkor/impu/impuppos.html

Convención Americana de DDHH. [CADDHH] (1969). Organización de Estados Americanos (OEA), Conferencia Especializada Interamericana sobre DDHH. http:// www.cidh.oas.org/Basicos/Spanish/Basicos2.htm

Convenio Europeo para la Protección de los DDHH y de las Libertades Fundamentales. [CEPDHLF] (1950). Consejo de Europa. http://www.echr.coe.int/Documents/ Convention_SPA.pdf

Declaración Universal de los DDHH. [DUDDHH] (1948). Organización de las Naciones Unidas (ONU), Comisión de DDHH. http://www.un.org/es/universal-declarationhuman-rights/

Declaración de las Naciones Unidas sobre los Principios Fundamentales de Justicia para las Víctimas de Delitos y del Abuso de Poder - resolución 40/34-. (1985). Asamblea General de la Organización de las Naciones Unidas (ONU). https://www. ohchr.org/sp/professionalinterest/pages/victimsofcrimeandabuseofpower.aspx

Pacto Internacional de Derechos Civiles y Políticos [PIDDCP] (Resolución 2200 A -XXI-). (1966). Asamblea General de las Naciones Unidas. http://www.corteconstitucional. gov.co/relatoria/PACTO\%20INTERNACIONAL\%20DE\%20DERECHOS\%20 CIVILES\%20Y\%20POLITICOS.php

Principios y directrices básicos sobre el Derecho de las Víctimas de violaciones manifiestas de las normas internacionales de DDHH y de violaciones graves del Derecho internacional humanitario a interponer recursos y obtener reparaciones -Resolución 60/147-. (2005b). Asamblea General de las Naciones Unidas. https:// www.ohchr.org/SP/Professionallnterest/Pages/RemedyAndReparation.aspx

\subsection{Jurisprudencia de la Corte IDH}

Corte IDH. (2001, 25 de Mayo) Caso de la "Panel Blanca" (Paniagua Morales y otros) Vs. Guatemala. Reparaciones y Costas. Serie C No. 76, párr. 79, 2001. https://www. corteidh.or.cr/docs/casos/articulos/Seriec_76_esp.pdf

Corte IDH (2008, 2 de mayo) Caso Kimel Vs. Argentina. Fondo, Reparaciones y Costas. Serie C No. 177. https://www.corteidh.or.cr/docs/casos/articulos/seriec_177_esp. pdf

Corte IDH (2009, 30 de junio) Caso Reverón Trujillo Vs. Venezuela. Excepción Preliminar, Fondo, Reparaciones y Costas. Serie C. No. 197. https://www.corteidh.or.cr/docs/ casos/articulos/seriec_197_esp.pdf

Corte IDH (2009, 24 de noviembre). Caso de la Masacre de Las Dos Erres Vs. Guatemala. Excepción Preliminar, Fondo, Reparaciones y Costas. Serie C No. 211. https://www. corteidh.or.cr/docs/casos/articulos/seriec_211_esp.pdf

Corte IDH (2010, 24 de noviembre) Caso Gomes Lund y otros ("Guerrilha do Araguaia") Vs. Brasil. Excepciones Preliminares, Fondo, Reparaciones y Costas. Serie C No. 219 https://www.corteidh.or.cr/docs/casos/articulos/seriec_219_esp.pdf

Corte IDH (2012, 24 de febrero) Caso Atala Riffo y Niñas vs. Chile: Fondo, Reparaciones y Costas. Serie C No. 239 http://corteidh.or.cr/docs/casos/articulos/seriec_239_esp. pdf 
Corte IDH (2012, 26 de junio). Caso Díaz Peña Vs. Venezuela. Excepción Preliminar, Fondo, Reparaciones y Costas. Serie C No. 244. http://corteidh.or.cr/docs/casos/ articulos/seriec_244_esp.pdf

Corte IDH (2014, 28 de agosto). Caso de Personas dominicanas y haitianas expulsadas Vs. República Dominicana. Excepciones Preliminares, Fondo, Reparaciones y Costas. Serie C No. 282. http://corteidh.or.cr/docs/casos/articulos/seriec_282_esp.pdf

Corte IDH (2017, 16 de febrero) Caso Favela Nova Brasilia Vs. Brasil. Excepciones Preliminares, Fondo, Reparaciones y Costas. Serie C No. 333. http://www.corteidh. or.cr/docs/casos/articulos/seriec_333_esp.pdf

Corte IDH (2017, 15 de noviembre). Caso Pacheco León y otros Vs. Honduras. Fondo, Reparaciones y Costas. Serie C No. 342. http://www.corteidh.or.cr/docs/casos/ articulos/seriec_342_esp.pdf

Corte IDH (2018, 8 de marzo). Caso V.R.P., V.P.C. y otros Vs. Nicaragua. Serie C No. 350. https://www.corteidh.or.cr/docs/casos/articulos/seriec_350_esp.pdf

Corte IDH (2018, 9 de marzo). Caso Ramírez Escobar y otros Vs. Guatemala. Serie C No. 351. https://www.corteidh.or.cr/docs/casos/articulos/seriec_351_esp.pdf

Corte IDH (2018, 13 de marzo). Caso Carvajal Carvajal y otros Vs. Colombia. Serie C No. 352. https://www.corteidh.or.cr/docs/casos/articulos/seriec_352_esp.pdf

Corte IDH (2018, 22 de agosto). Caso Coc Max y otros (Masacre de Xamán) Vs. Guatemala. Serie C No. 356. https://www.corteidh.or.cr/docs/casos/articulos/seriec_356_esp. pdf

Corte IDH (2018, 23 de agosto). Caso Cuscul Pivaral y otros Vs. Guatemala. Serie C No. 359. https://www.corteidh.or.cr/docs/casos/articulos/seriec_359_esp.pdf

Corte IDH (2018, 26 de septiembre) Caso Escaleras Mejía y otros Vs. Honduras. Serie C No. 361. https://www.corteidh.or.cr/docs/casos/articulos/seriec_361_esp.pdf

Corte IDH (2018, 20 de noviembre). Caso Isaza Uribe y otros Vs. Colombia. Serie C No. 363. https://www.corteidh.or.cr/docs/casos/articulos/seriec_363_esp.pdf

Corte IDH (2018, 29 de noviembre). Caso Órdenes Guerra y otros Vs. Chile. Serie C No. 372. https://www.corteidh.or.cr/docs/casos/articulos/seriec_372_esp.pdf 